\title{
Nasal inflammation and its response to local glucocorticoid regular treatment in patients with persistent non-allergic rhinitis: a pilot study
}

Donatella Poletti ${ }^{1}$, Valeria lannini ${ }^{6}$, Paolo Casolari ${ }^{5}$, Marco Contoli ${ }^{5}$, Alberto Papi ${ }^{5}$, Paul Kirkham², Trevor T. Hansel ${ }^{4}$, Kian Fan Chung ${ }^{3}$, Peter J. Barnes ${ }^{3}$, Antonio Pastore ${ }^{6}$, Stefano Pelucchi ${ }^{6}$, lan M. Adcock ${ }^{3}$ and Gaetano Caramori ${ }^{5^{*}}$ (D)

\begin{abstract}
Background: The pathogenesis of non-allergic rhinitis (NAR) is still largely unknown. Furthermore, it is unclear whether there is a correlation between the effect of nasal glucocorticoids on nasal inflammation and on nasal symptoms and quality of life.
\end{abstract}

Methods: In this pilot study we recruited 12 healthy subjects and 24 patients with recently diagnosed persistent NAR [12 untreated and 12 under regular treatment with nasal fluticasone furoate (two sprays of $27.5 \mu \mathrm{g}$ each in each nostril once daily, total daily dose $=110 \mu \mathrm{g}$ ) for at least 20 days]. Each subject filled a mini rhinoconjunctivitis quality of life questionnaire (mini RQLQ). Nasal scrapings were obtained from each subject and used to prepare slides for Diff-Quik and immunocytochemical staining for inflammatory and epithelial cells count, MUC5AC expression and the general pro-inflammatory transcription factor nuclear factor kB (NF-kB) activation.

Results: The nasal score of the mini RQLQ, the number of nasal inflammatory cells (neutrophils, eosinophils) and the number of goblet cells are significantly higher in untreated patients with persistent NAR compared with control subjects and treated NAR patients. The percentage of MUC5AC+ nasal epithelial cells is significantly increased in untreated patients with persistent NAR compared with the control subjects ( $41.8 \pm 6.4$ vs $22.3 \pm 4.8$, respectively; $p=0.0403$ ) without significant differences between control subjects and patients with persistent NAR on regular fluticasone furoate treatment $(33.9 \pm 5.0 \% ; p=0.0604)$ nor between the 2 groups of persistent NAR subjects $(p=0.3260)$. The number of cytosolic and/or nuclear p65+ nasal epithelial and inflammatory cells was not significantly different between the three groups.

Conclusions: Patients with persistent untreated NAR, compared with normal control subjects and patients with persistent NAR under regular treatment with nasal fluticasone furoate by at least 20 days, have more nasal symptoms, worst quality of life and an increased number of nasal inflammatory cells (neutrophils, eosinophils), goblet cells and MUC5AC+ nasal epithelial cells. This nasal inflammation seems unrelated to NF-kB activation.

Keywords: Non-allergic rhinitis, Nasal scraping, Nasal inflammation, Nasal epithelial cells, Goblet cells, MUC5AC, p65, Eosinophils

\footnotetext{
* Correspondence: gaetano.caramori@unife.it

${ }^{5}$ Centro Interdipartimentale per lo Studio delle Malattie Infiammatorie delle

Vie Aeree e Patologie Fumo-correlate (CEMICEF), Dipartimento di Scienze

Mediche, Sezione di Medicina Interna e Cardiorespiratoria, Università di

Ferrara, Via Ludovico Ariosto 35, 44121 Ferrara, Italy

Full list of author information is available at the end of the article
} 


\section{Background}

Non-allergic rhinitis (NAR) is a term that can be applied to any disease of the nose presenting with obstructive and secretory symptoms, with or without hyperirritability, that does not have a known allergic [immunoglobulin (Ig)Emediated)] etiology. In fact, the disease is "non-allergic" when allergy has not been proven by proper allergy examination (history, skin prick testing, measurement of serum specific IgE antibodies) [1]. This definition can be narrowed by allowing only chronic conditions to be included and, therefore, by excluding acute viral and acute bacterial infections [1]. The pathogenesis of persistent (chronic) NAR is still largely unknown [2].

Nasal cytology, obtained using nasal scraping, is a promising, scarcely invasive, tool to investigate nasal inflammation, but most of the studies have been performed so far in patients with allergic rhinitis only [3]. The aim of this study was to investigate, using nasal cytology, inflammatory cell counts, the activation of the general pro-inflammatory transcription factor nuclear factor $\mathrm{kB}(\mathrm{NF}-\mathrm{kB})$ and the expression of MUC5AC (the main secretory mucin expressed on the surface of the nasal epithelium), in patients with untreated persistent NAR and a control group of normal subjects and to investigate the response to the regular treatment with endonasal glucocorticoids, the gold standard treatment, in a separate cohort of patients with persistent NAR under regular treatment with nasal glucocorticoids by at least 20 days. We also have correlated these results with the quality of life of the subjects using a validated questionnaire.

\section{Methods}

The study was approved by the local ethics committee of the University Hospital of Ferrara, Italy (www.ospfe.it), and informed consent was obtained from each participant in accordance with the principles outlined in the Declaration of Helsinki.

We recruited 3 groups of subjects, aged between 18 and 65 , all lifelong non-smokers, nonatopic [negative skin prick tests and/or RAST for the most common aeroallergens in Italy (house-dust mites (Dermatophagoides pteronyssinus and farinae), cat and dog dander, plant pollens (grass mix, Parietaria, Olea europaea, Cupressus sempervirens, Betula pendula, Corylus avellana, Artemisia vulgaris) and molds (Alternaria tenuis, Aspergillus fumigatus and Cladosporium herbarum)] and non-asthmatic. Their demographic characteristics are summarised in Table 1 . There is a significant difference in the mean age between the healthy control group and the patients with $\mathrm{NAR}+$ nasal fluticasone furoate (FF) $(32.5 \pm 2.7$ vs $48.1 \pm 4.0$, respectively; $95 \%$ confidence interval $26.6-38.4$ vs $39.2-56.9$, respectively; Mann-Whitney U test $p=0.0091$ ).
Table 1 Study subjects demographic characteristics

\begin{tabular}{|c|c|c|c|c|}
\hline & $n$ & Age & Sex & $\begin{array}{l}\text { Mini-RQLQ } \\
\text { score }\end{array}$ \\
\hline Healthy control group & 12 & $32.5 \pm 2.7$ & $4 \mathrm{M} / 8 \mathrm{~F}$ & $8.1 \pm 4.4$ \\
\hline Nonallergic persistent rhinitis & 12 & $39.5 \pm 3.7$ & $4 \mathrm{M} / 8 \mathrm{~F}$ & $32.9 \pm 5.6$ \\
\hline $\begin{array}{l}\text { Nonallergic persistent rhinitis } \\
+ \text { nasal FF }\end{array}$ & 12 & $48.1 \pm 4.0$ & $5 \mathrm{M} / 7 \mathrm{~F}$ & $15.7 \pm 4.7$ \\
\hline
\end{tabular}

The healthy subjects in the control group $(n=12$, mean age $32.5 \pm 2.7 ; 4 \mathrm{M} / 8 \mathrm{~F}$ ) were all non-rhinitics and free from any other nasal disease. A group $(n=12)$ of patients were recruited with persistent untreated nonallergic rhinitis (mean age $39.5 \pm 3.7 ; 4 \mathrm{M} / 8 \mathrm{~F}$ ). None of these patients or control subjects had been treated in the least 60 days with systemic and/or nasal glucocorticoids, anti-histamine 1 receptor drugs, anti-leukotrienes, methylxanthines, or any kind of immunosuppressing drugs, mucolytics/antioxidants drugs by systemic or local routes.

A separate second cohort $(n=12)$ of patients with chronic non-allergic rhinitis (mean age $48.1 \pm 4.0 ; 5 \mathrm{M}$ / $7 \mathrm{~F})$ were treated regularly for at least 20 days with nasal fluticasone furoate (two sprays of $27.5 \mu \mathrm{g}$ each, in each nostril once daily, total daily dose $=110 \mu \mathrm{g}$ ) but not antihistamine 1 receptor drugs and/or anti-leukotrienes, methylxanthines, or any kind of other immunosuppressing drugs, mucolytics/antioxidants drugs by systemic or local routes. All NAR patients in both groups were initially diagnosed within 12 months of their recruitment to the study.

Both groups of patients with persistent non-allergic rhinitis have been previously investigated with nasal endoscopy and maxillofacial computed tomography to exclude the presence of rhinosinusal polyposis and all these patients have never been previously treated with nasal or sinus surgery.

Each subject recruited to the study completed the mini rhinoconjunctivitis quality of life questionnaire (mini RQLQ) [4] (the permission to use the Italian validated version of this questionnaire was kindly given to GC by Prof. Elizabeth Juniper; https:// www.qoltech.co.uk/mini_rqlq.html) (Table 2 in supplementary material).

\section{Nasal scrapings and nasal cytology}

Each subject recruited to the study underwent a single nasal scraping. The nasal scraping was performed under direct visual inspection using a plastic curette in the middle third of the inferior turbinate, an area previously reported to have an optimal ratio between ciliated and mucous-secreting cells, usually in favour of ciliated cells [5]. There is no single published standardized protocol for processing these samples and for this reason we have followed the guidelines for sputum processing. 
Table 2 Italian validated version of the Mini Rhinoconjunctivitis Quality of Life Questionnaire (MiniRQLQ)

\begin{tabular}{|c|c|c|c|c|c|c|c|}
\hline & $\begin{array}{l}\text { Nessun } \\
\text { fastidio }\end{array}$ & $\begin{array}{l}\text { Quasi nessun } \\
\text { fastidio }\end{array}$ & $\begin{array}{l}\text { Un leggero } \\
\text { fastidio }\end{array}$ & $\begin{array}{l}\text { Poco } \\
\text { fastidio }\end{array}$ & $\begin{array}{l}\text { Abbastanza } \\
\text { fastidio }\end{array}$ & $\begin{array}{l}\text { Molto } \\
\text { fastidio }\end{array}$ & $\begin{array}{l}\text { Moltissimo } \\
\text { fastidio }\end{array}$ \\
\hline \multicolumn{8}{|l|}{ Attività } \\
\hline I. Attività regolari a casa e al lavoro & 0 & 1 & 2 & 3 & 4 & 5 & 6 \\
\hline \multicolumn{8}{|l|}{$\begin{array}{l}\text { (il lavoro o le faccende che deve } \\
\text { svolgere regolarmente in casa) }\end{array}$} \\
\hline 2. Attività sociali & 0 & 1 & 2 & 3 & 4 & 5 & 6 \\
\hline \multicolumn{8}{|l|}{$\begin{array}{l}\text { (es., attività con la famiglia e gli amici, } \\
\text { giocare con i bambini e gli animali } \\
\text { domestici, rapporti sessuali, passatempi) }\end{array}$} \\
\hline 3. Attività all'aperto & 0 & 1 & 2 & 3 & 4 & 5 & 6 \\
\hline \multicolumn{8}{|l|}{$\begin{array}{l}\text { (es., giardinaggio, tagliare il prato, stare } \\
\text { seduti all'aperto, praticare sport, fare } \\
\text { una passeggiata) }\end{array}$} \\
\hline \multicolumn{8}{|l|}{ Sonno } \\
\hline 4. Difficoltà a prendere sonno & 0 & 1 & 2 & 3 & 4 & 5 & 6 \\
\hline 5. Svegliarsi durante la notte & 0 & 1 & 2 & 3 & 4 & 5 & 6 \\
\hline 6. Mancanza di una buona dormita & 0 & 1 & 2 & 3 & 4 & 5 & 6 \\
\hline \multicolumn{8}{|l|}{ Problemi generali } \\
\hline 7. Affaticamento (mancanza di energia) & 0 & 1 & 2 & 3 & 4 & 5 & 6 \\
\hline 8. Sete & 0 & 1 & 2 & 3 & 4 & 5 & 6 \\
\hline 9. Produttività ridotta & 0 & 1 & 2 & 3 & 4 & 5 & 6 \\
\hline 10. Sentirsi assonnato/a & 0 & 1 & 2 & 3 & 4 & 5 & 6 \\
\hline 11. Scarsa concentrazione & 0 & 1 & 2 & 3 & 4 & 5 & 6 \\
\hline 12. Mal di testa & 0 & 1 & 2 & 3 & 4 & 5 & 6 \\
\hline 13. Sfinimento, spossatezza & 0 & 1 & 2 & 3 & 4 & 5 & 6 \\
\hline \multicolumn{8}{|l|}{ Problemi pratici } \\
\hline $\begin{array}{l}\text { 14. La scomodità di dover portare con sé } \\
\text { fazzoletti o fazzolettini di carta }\end{array}$ & 0 & 1 & 2 & 3 & 4 & 5 & 6 \\
\hline 15. Il bisogno di strofinarsi il naso o gli occhi & 0 & 1 & 2 & 3 & 4 & 5 & 6 \\
\hline 16. II bisogno di soffiarsi ripetutamente il naso & 0 & 1 & 2 & 3 & 4 & 5 & 6 \\
\hline \multicolumn{8}{|l|}{ Disturbi nasali } \\
\hline 17. Naso chiuso & 0 & 1 & 2 & 3 & 4 & 5 & 6 \\
\hline 18. Naso che cola & 0 & 1 & 2 & 3 & 4 & 5 & 6 \\
\hline 19. Starnuti & 0 & 1 & 2 & 3 & 4 & 5 & 6 \\
\hline 20. Catarro in gola & 0 & 1 & 2 & 3 & 4 & 5 & 6 \\
\hline \multicolumn{8}{|l|}{ Disturbi agli occhi } \\
\hline 21. Prurito agli occhi & 0 & 1 & 2 & 3 & 4 & 5 & 6 \\
\hline 22. Occhi che lacrimano & 0 & 1 & 2 & 3 & 4 & 5 & 6 \\
\hline 23. Occhi irritati & 0 & 1 & 2 & 3 & 4 & 5 & 6 \\
\hline 24. Occhi gonfi & 0 & 1 & 2 & 3 & 4 & 5 & 6 \\
\hline \multicolumn{8}{|l|}{ Aspetti emotivi } \\
\hline 25. Si è sentito/a contrariato/a e deluso/a & 0 & 1 & 2 & 3 & 4 & 5 & 6 \\
\hline 26. Impazienza e inquietudine & 0 & 1 & 2 & 3 & 4 & 5 & 6 \\
\hline 27. Irritabilità & 0 & 1 & 2 & 3 & 4 & 5 & 6 \\
\hline 28. Imbarazzo a causa dei disturbi & 0 & 1 & 2 & 3 & 4 & 5 & 6 \\
\hline
\end{tabular}


Nasal scrapes were immediately put onto ice and maintained at $4^{\circ} \mathrm{C}$ throughout their processing. Each nasal scraping was processed by cytocentrifugation, to obtain at least 4 cytospins from each subject. Cytospin slides were prepared and dried for $30 \mathrm{~min}$. An average of at least six slides were prepared from each patient. Two of these cytospins were stained using Diff-Quik method exactly according to the Manufacturer's instructions (Dade Behring, Milan Italy) for total and differential cell counts. The remaining slides were wrapped in aluminum foil and stored at $-20{ }^{\circ} \mathrm{C}$ before immunocytochemical staining for MUC5AC and $\mathrm{p} 65$.

\section{Immunocytochemistry for MUC5AC and p65 in nasal cytospins}

We used a protocol previously described [6]. Nasal cytospins were fixed with $4 \%$ paraformaldehyde (PFA, $10 \mathrm{~min}, 22^{\circ} \mathrm{C}$ ), washed (PBS $1 \mathrm{X}$, twice for $5 \mathrm{~min}, 22^{\circ} \mathrm{C}$ ), and cells permeabilized (acetone/methanol, $10 \mathrm{~min}$, $-20{ }^{\circ} \mathrm{C}$ ). The cell endogenous peroxidase activity was quenched ( $3 \%$ hydrogen peroxide, $30 \mathrm{~min}, 22{ }^{\circ} \mathrm{C}$ ). Nonspecific binding was blocked (5\% normal horse serum or $5 \%$ normal goat serum, $20 \mathrm{~min}, 22{ }^{\circ} \mathrm{C}$ ) before incubation with the specific mouse anti-MUC5AC clone $45 \mathrm{M} 1$ (sc-21701, Santa Cruz Biotechnology, USA; 1:1100 dilution, $1 \mathrm{~h}, 22{ }^{\circ} \mathrm{C}$ ) or rabbit anti-p65 (sc-372, Santa Cruz Biotechnology, USA; 1:100 dilution, $1 \mathrm{~h}, 22^{\circ} \mathrm{C}$ ). The selectivity of both these primary antibodies has been previously described $[6,7]$. We did not performed the immunocytochemical staining for MUC5B because in a separate pilot study we did not observe any MUC5B+ staining in nasal epithelial cells from either normal subjects or patients with persistent untreated or treated NAR using appropriate positive controls and a validated primary antibody [8].

Both MUC5AC and p65 were detected using peroxidase (Vectastain Elite ABC-Peroxidase Kit Standard, Vector Laboratories, Burlingame, CA, USA) and DAB substrate according to the Manufacturer's instructions. Negative control slides (nonspecific immunoglobulin of the same isotype of the primary antibody) were included in each staining run for each patient for every group of subjects (control subjects, untreated and treated patients with persistent NAR).

\section{Cell count}

Cell counts were performed on the Diff-Quik-stained slides using an optical microscope at a x1000 total magnification, by two independent blinded observers (PC and VI). The mean intra-observer coefficients of variance with counting were less than $10 \%$. To have a more complete data set we counted all cells within specific grids on each slide (total number of cells), distinguishing and counting inflammatory and nasal epithelial cells, the different subsets of inflammatory cells and the number of goblet cells among the nasal epithelial cells.

Goblet cells were defined as glandular, modified simple columnar epithelial cells [9].

The total cell count was standardized for the sample size $(\mathrm{ml})$ as previously described [6].

All MUC5AC+ and p65+ cells staining brown, indicating MUC5AC or p65 immunoreactivity, were counted on each slide. p65+ cells were also quantified for cytoplasmic and/or nuclear (an index of activation) staining.

\section{Statistical analysis}

Group data were expressed as mean and standard error (SEM). The Kruskal-Wallis test for nonparametric data followed by Mann-Whitney U test was used to determine differences between the three groups of subjects and the post-test Dunn's comparison. A probability value of $<0.05$ was considered significant.

\section{Results \\ Clinical parameters}

The total mini RQLQ score was significantly increased in the patients with untreated persistent NAR compared both to the control normal subjects and the patients with persistent NAR under regular treatment with FF $(32.9 \pm 5.6$ vs $8.1 \pm 4.4$ vs $15.7 \pm 4.7$, respectively; $95 \%$ confidence interval $20.6-45.3$ vs $-1.7-17.8$ vs 5.4-26.0, respectively; Mann-Whitney U test $\mathrm{p}=0.0011$ and $p=0.0224$, respectively; one-way ANOVA Dunn's multiple comparison test NAR vs NAR + FF $p>0.05$ ), without significant differences between control subjects and patients with persistent NAR under regular treatment with nasal FF (Mann-Whitney U test $p=0.0878$ ) (Kruskal-Wallis test $\mathrm{p}=0.0017$ ) (Fig. 1a).

The nasal symptoms (sneezing, stuffy blocked nose, runny nose) score was significantly increased in the patients with untreated persistent NAR compared both to the control normal subjects and the patients with persistent NAR under regular treatment with nasal FF $(9.0 \pm 1.7$ vs $2.0 \pm 1.1$ vs $4.3 \pm 1.2$, respectively; $95 \%$ confidence interval $5.2-12.8$ vs $-0.3-4.3$ vs $1.7-7.0$, respectively; Mann-Whitney $\mathrm{U}$ test $p=0.0015$ and $p=0.0367$, respectively; one-way ANOVA Dunn's multiple comparison test NAR vs NAR + FF $p>0.05$ ), without significant differences between control subjects and patients with persistent NAR under regular treatment with nasal glucocorticoids (Mann-Whitney $\mathrm{U}$ test $p=0.1280$ ) (Kruskal-Wallis test $p=0.0032$ ) (Fig. 1b). Furthermore, all patients with persistent NAR (both untreated and treated) showed a statistically significant worse daily activity score compared to the control group of normal subjects $(6.9 \pm 1.5$ vs $4.1 \pm 1.2$ vs $1.4 \pm 0.8$, respectively; $95 \%$ confidence interval 3.6- 10.3 vs $1.5-6.7$ vs $-0.4-3.2$, respectively; Mann-Whitney $\mathrm{U}$ test $p=0.0022$ and $p=0.0357$, 


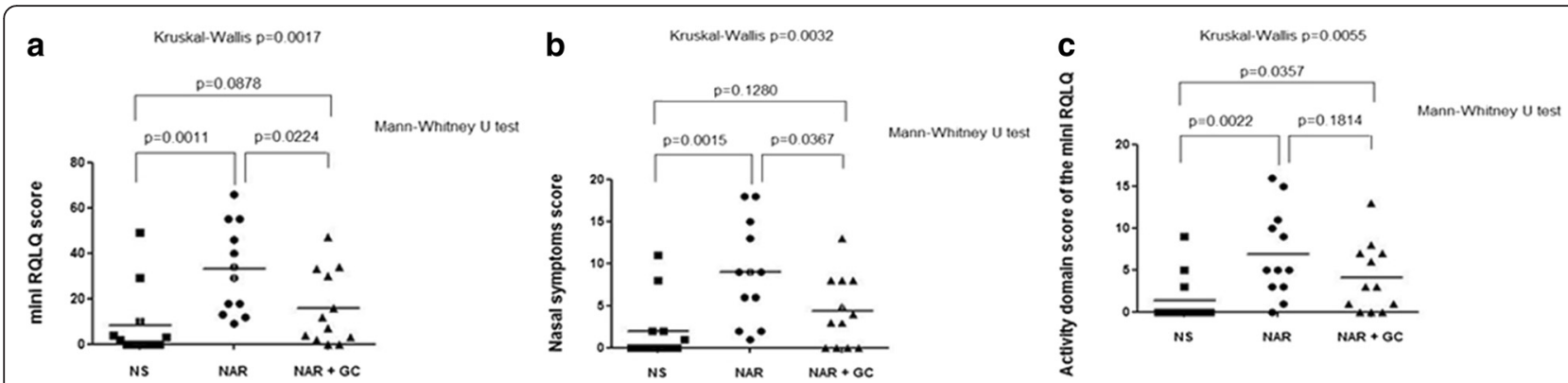

Fig. 1 a) The mini RQLQ total score is significantly increased in the persistent untreated nonallergic rhinitis (NAR) patients compared both to control normal subjects (NS) and the persistent NAR patients under regular treatment with nasal glucocorticoids (NAR + GC), without any significant difference between control subjects and persistent NAR patients under regular treatment with nasal glucocorticoids. b) The nasal symptoms score of the mini RQLQ is significantly increased in the persistent untreated NAR patients compared both to NS and NAR + GC, without any significant difference between control subjects and persistent NAR patients under regular treatment with nasal glucocorticoids. c) The interference of rhinitis pathology with the daily activities score of the mini RQLQ is significantly increased both in the persistent untreated NAR patients and NAR + GC compared with NS, without any significant difference between both groups of persistent NAR patients

respectively; one-way ANOVA Dunn's multiple comparison test control group vs NAR + FF $p>0.05$ ) (Fig. 1c) although this score, considered as "the interference of rhinitis pathology with the daily activities", was not significantly affected by topical FF therapy and was not different between the 2 groups of persistent NAR subjects (Mann-Whitney U test $p=0.1814$ ) (KruskalWallis test $p=0.0055)$.

\section{Total and differential nasal inflammatory cells count}

The total number of nasal inflammatory cells count (Fig. 2a) was significantly increased in patients with untreated persistent NAR compared both to the control normal subjects and patients with persistent NAR treated with nasal FF $(43.5 \pm 18.6$ vs $0.0 \pm 0.0$ vs $19.3 \pm$ 14.6, respectively; $95 \%$ confidence interval $2.6-84.4$ vs $0.0-0.0$ vs $-13.0-51.5$, respectively; Mann-Whitney U test $p=0.0001$ and $p=0.0165$, respectively; two-way ANOVA Bonferroni multiple comparison column factor $\mathrm{p}=0.1040)$. There were no significant differences between control subjects and NAR patients on nasal FF (Mann-Whitney $\mathrm{U}$ test $p=0.0788$ ) (Kruskal-Wallis test $p=0.0002)$ (Fig. 2b).

The percentage of nasal neutrophils was significantly increased in patients with untreated persistent NAR compared both to the control normal subjects and NAR patients on nasal FF $(65.3 \pm 12.5$ vs $0.0 \pm 0.0$ vs $16.7 \pm$ $11.2 \%$, respectively; $95 \%$ confidence interval $37.8-92.9$ vs $-0.0-0.0$ vs $-8.1-41.4$, respectively; Mann-Whitney $\mathrm{U}$ test $p=0.0001$ and $p=0.0098$, respectively) (KruskalWallis test $p=0.0001$ ) (Fig. 3a).

The percentage of nasal eosinophils was also significantly increased in the patients with untreated persistent NAR compared to the control normal subjects (18.0 \pm 9.2 vs $0.0 \pm 0.0 \%$, respectively; $95 \%$ confidence interval $-2.3-38.3$ vs $-0.0-0.0$, respectively; MannWhitney $\mathrm{U}$ test $p=0.0071$; two-way ANOVA Bonferroni multiple comparison column factor $p=0.2569$ )
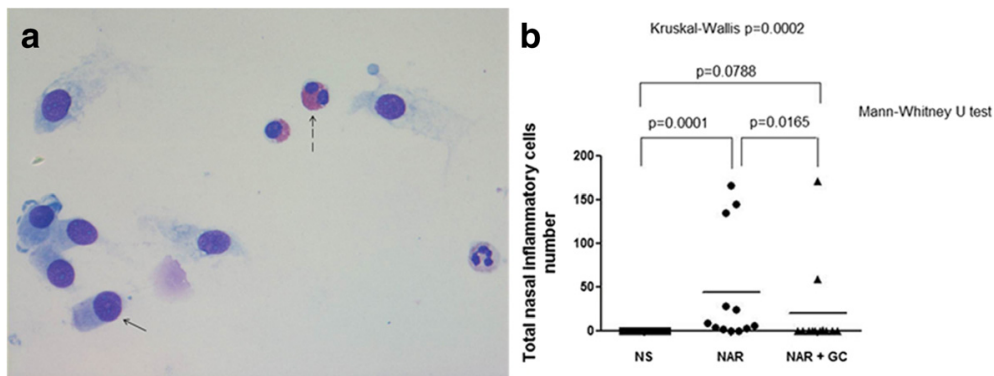

Fig. 2 a) Diff-Quik staining of a nasal cytospin showing nasal ciliated epithelial cells (arrow) and nasal inflammatory cells (eosinophils and neutrophils) stained with Diff-Quik. The nuclei and cytosol of the epithelial cells and neutrophils are stained in purple/blue, cytosol of eosinophil granules is stained in red (broken arrow). Original magnification: $\times 400$. b) The total number of nasal inflammatory cells is significantly increased in the persistent untreated nonallergic rhinitis (NAR) patients compared both to control normal subjects (NS) and the persistent NAR patients under regular treatment with nasal glucocorticoids $(N A R+G C$ ), without any significant difference between control subjects and persistent NAR patients under regular treatment with nasal glucocorticoids 

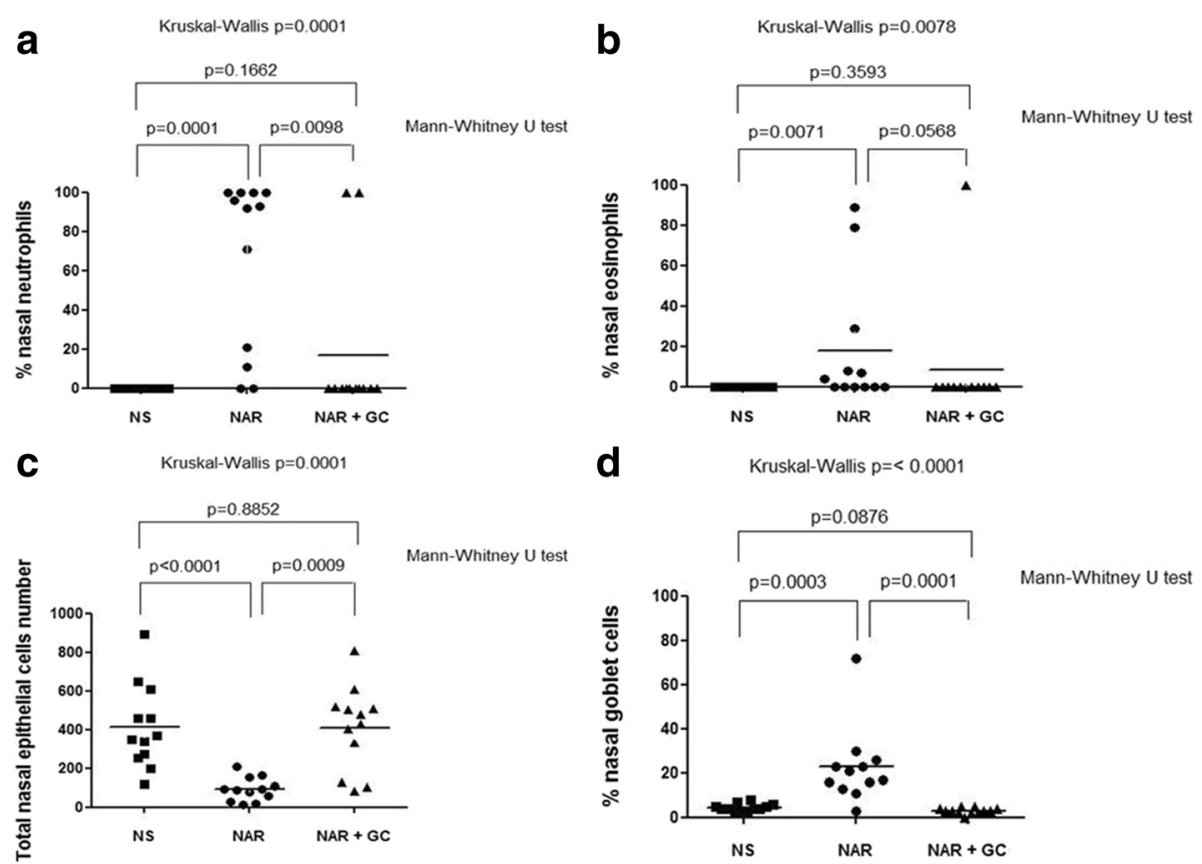

Fig. 3 a) The percentage of neutrophils on total number of nasal inflammatory cells is significantly increased in the persistent untreated nonallergic rhinitis (NAR) patients compared both to control normal subjects (NS) and the persistent NAR patients under regular treatment with nasal glucocorticoids (NAR+GC), without any significant difference between control subjects and persistent NAR patients under regular treatment with nasal glucocorticoids. b) The percentage of eosinophils on total number of nasal inflammatory cells is significantly increased in the persistent untreated NAR patients compared both to NS and NAR + GC, without any significant difference between control subjects and persistent NAR patients under regular treatment with nasal glucocorticoids. c) The total number of nasal epithelial cells is significantly increased in the persistent untreated NAR patients compared both to NS and NAR $+G C$, without any significant difference between control subjects and persistent NAR patients under regular treatment with nasal glucocorticoids. d) The percentage of goblet cells on the total number of nasal epithelial cells is significantly increased in the persistent untreated NAR patients compared both to NS and NAR + GC, without any significant difference between control subjects and persistent NAR patients under regular treatment with nasal glucocorticoids

without significant differences between control subjects and patients with persistent NAR under regular treatment with nasal FF $(8.3 \pm 8.3 \%$; $95 \%$ confidence interval $-10.0-26.7$; Mann-Whitney U test $p=0.3593$ ) nor between the 2 groups of persistent NAR subjects (Mann-Whitney U test $p=0.0568$ ) (Kruskal-Wallis test $p=0.0078)$ (Fig. 3b).

\section{Total nasal epithelial cells and nasal goblet cells count}

The total number of nasal epithelial cells count was significantly different between patients with persistent untreated NAR compared both to the control normal subjects and NAR patients treated with nasal FF (92.3 \pm 17.2 vs $413.8 \pm 62.8$ vs $407.8 \pm 62.6$, respectively; $95 \%$ confidence interval $54.4-130.2$ vs $275.7-551.9$ vs 270.0 - 545.7, respectively; Mann-Whitney U test $p<$ 0.0001 and $p=0.0009$, respectively) with no significant differences between control subjects and nasal FFtreated NAR patients (Mann-Whitney $\mathrm{U}$ test $p=0.8852$ ) (Kruskal-Wallis test $p=0.0001$ ) (Fig. 3c).

The percentage of nasal goblet cells was significantly enhanced in untreated NAR patients compared to either control normal subjects and NAR patients treated with nasal $\mathrm{FF}(22.6 \pm 5.0$ vs $4.4 \pm 0.6$ vs $3.0 \pm 0.4 \%$, respectively; $95 \%$ confidence interval $11.7-33.5$ vs $3.2-5.6$ vs 2.1-3.9, respectively; Mann-Whitney $\mathrm{U}$ test $p=0.0003$ and $p=0.0001$, respectively). No significant differences between control subjects and nasal FF-treated NAR patients was observed (Mann-Whitney $\mathrm{U}$ test $p=0.0876$ ) (Kruskal-Wallis test $p<0.0001$ ) (Fig. 3d).

\section{Nasal epithelial cells MUC5AC+ count}

The immunoreactivity for MUC5AC in the nasal epithelial cells was localized to both goblet and non-goblet cells (Fig. 4a).

The percentage of MUC5AC+ nasal epithelial cells over the total number of nasal epithelial cells was significantly increased in untreated NAR patients compared to control normal subjects $(41.8 \pm 6.4$ vs $22.3 \pm 4.8 \%$, respectively; $95 \%$ confidence interval $27.7-55.8$ vs 11.6 - 32.9, respectively; Mann-Whitney $\mathrm{U}$ test $p=0.0403$; one-way ANOVA Dunn's multiple comparison test $p>0.05$ ). There were no significant differences between control subjects and NAR patients on nasal FF $(33.9 \pm 5.0 \%$; $95 \%$ confidence interval 23.0-44.8; Mann-Whitney $\mathrm{U}$ test $p=0.0604$ ) 


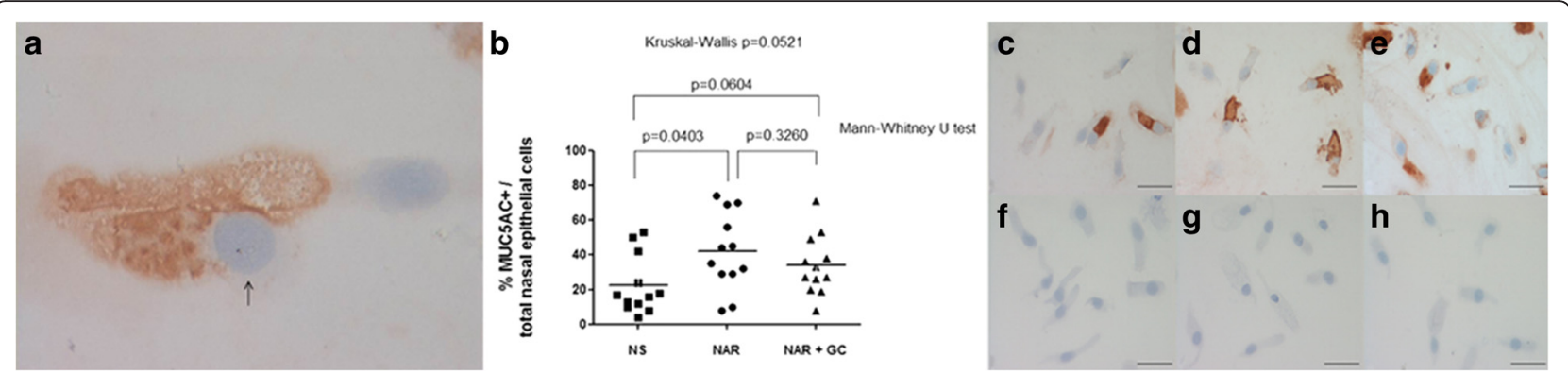

Fig. 4 a) Photomicrograph showing a nasal epithelial cell immunostained for identification of MUC5AC+ cells. Nuclei are stained in purple/blue (arrow), cytoplasmic mucin MUC5AC is stained in brown. b) The percentage of MUC5AC+ nasal epithelial cells over the total number of nasal epithelial cells is significantly increased in the persistent untreated nonallergic rhinitis (NAR) patients compared both to control normal subjects (NS) and the persistent NAR patients under regular treatment with nasal glucocorticoids (NAR+GC), without any significant difference between control subjects and persistent NAR patients under regular treatment with nasal glucocorticoids. The immunocytochemical images in the right panel are representative of those from 12 control group subjects (c), 12 patients with persistent untreated NAR (d) and 12 patients with persistent NAR under regular treatment with nasal glucocorticoids (e). The images $\mathbf{f}, \mathbf{g}$ and $\mathbf{h}$ are their representative negative controls (nonspecific mouse $\lg G$ ). Original magnification: $\mathbf{x} 400$. Bar $=50 \mu \mathrm{m}$

nor between the 2 groups of persistent NAR subjects (Mann-Whitney $\mathrm{U}$ test $p=0.3260$ ) (Kruskal-Wallis test $p=0.0521$ ) (Fig. 4b-h).

\section{Nasal epithelial and inflammatory cells p65+ count}

p65+ nuclear and cytoplasmic staining was observed in nasal epithelial cells (Fig. 5a-f). There was no difference between any of the groups studied with respect to cytosolic and/or nuclear p65 staining (Fig. $5 \mathrm{~g}$ and $\mathrm{h}$ ). In detail, the percentage of cytosolic $(42.5 \pm 3.8$ vs $45.2 \pm$ 4.2 vs $41.2 \pm 2.5 \%$, untreated persistent NAR patients vs control normal subjects vs NAR patients under regular FF treatment, respectively; $95 \%$ confidence interval $34.2-50.8$ vs $35.8-54.5$ vs $35.7-46.7$, respectively; Kruskal-Wallis test $p=0.9270)$ and nuclear $(0.03 \pm 0.03$ vs $0.1 \pm 0.09$ vs $0.0 \pm 0.0 \%$, untreated persistent NAR patients vs control normal subjects vs NAR patients under regular FF treatment, respectively; $95 \%$ confidence interval $-0.03-0.08$ vs $-0.07-0.3$ vs $0.0-0.0$, respectively; Kruskal-Wallis test $p=0.3262) \mathrm{p} 65+$ nasal epithelial cells compared with the total number of nasal epithelial cells did not differ significantly between the 3 subject groups. In addition, no difference in these parameters were observed for the nasal inflammatory cells.

\section{Correlations between inflammatory cells and MUC5AC expression}

There was no significant correlation between the number and/or type of inflammatory cells and MUC5AC expression in the nasal epithelial cells. In addition the outliers in the number of inflammatory cells and in the MUC5AC expression in the nasal epithelial cells were not the same patients.

\section{Discussion}

We have shown here for the first time that patients with untreated persistent NAR, compared to control normal subjects, have an increased number of nasal inflammatory cells (both neutrophils and/or eosinophils) and nasal goblet cells and that the regular treatment with nasal FF for at
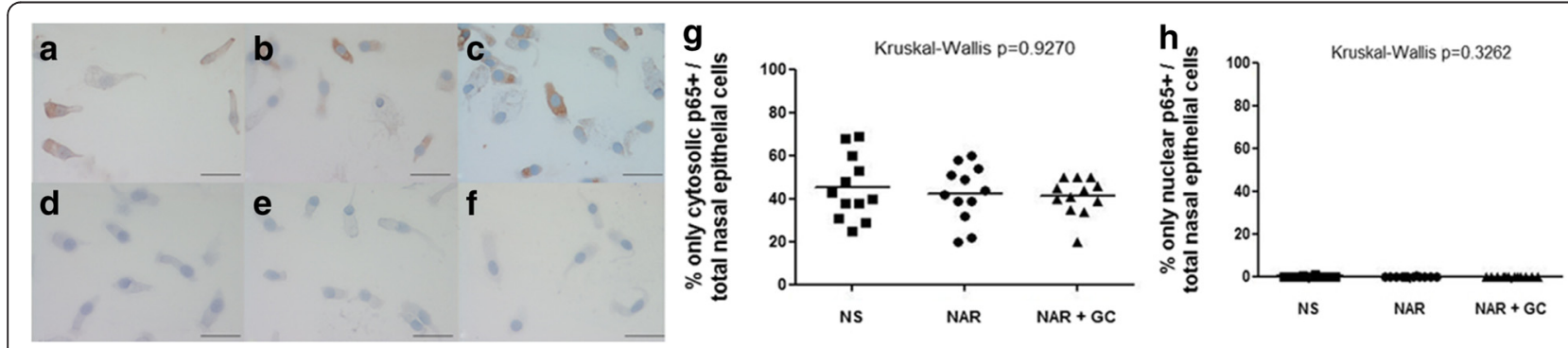

Fig. 5 a) Photomicrographs showing nasal epithelial cells immunostained for identification of p65+ cells. Nuclei are stained in purple/blue, p65 is stained in brown. The immunocytochemical images in the left panel are representative of those from 12 control normal subjects (NS) (A), 12 patients with persistent untreated nonallergic rhinitis (NAR) patients $(\mathbf{b})$ and 12 patients with persistent NAR patients under regular treatment with nasal glucocorticoids (NAR+GC) (c). The images $\mathbf{d}$, e and $\mathbf{f}$ are the negative controls (nonspecific rabbit lgG). Original magnification: $\times 400$. Bar $=50 \mu \mathrm{m}$. The percentage of cytosolic only p65+ nasal epithelial cells $(\mathbf{g})$ and nuclear p65+ nasal epithelial cells (h) over total nasal epithelial cells is not significantly different between persistent untreated NAR patients, NS and NAR + GC 
least 20 days, is associated with a significant reduction in the number of these inflammatory cells as previously observed in controlled clinical trials performed in patients with chronic allergic rhinitis [10]. In addition we have also shown for the first time a significant increase in the number of MUC5AC+ nasal epithelial cells in patients with untreated persistent NAR, compared with control normal subjects, whereas their number is not significantly different between control subjects and persistent NAR patients under regular treatment with nasal FF.

The effect of the glucocorticoids on MUC5AC expression is still quite controversial. In vitro the effects of glucocorticoids on the expression of MUCAC appear celltype dependent. For example, fluticasone propionate significantly reduced MUC5AC protein expression in the human lung mucoepidermoid carcinoma cell line (H292 cells) [11], whereas a treatment with dexamethasone did not change significantly the steady-state messenger ribonucleic acid (mRNA) levels of MUC5AC in cultured human nasal epithelial cells obtained from nasal polyps [12] and even enhanced both MUC5AC protein secretion and MUC5AC mRNA expression in cultured normal human bronchial epithelial cells [13-15]. In addition, in an animal model of rhinovirus infection fluticasone propionate increased MUC5AC protein level in the bronchoalveolar lavage [16].

Tang et al. reported a significant decrease in MUC5AC mRNA in human nasal epithelial cells and of MUC5AC expression in nasal mucosal biopsy specimens in patients with allergic rhinitis after treatment with fluticasone propionate $(100 \mu \mathrm{g}$ of nasal spray per nostril once daily for 4 weeks). In this report, patients with traumatic optic neuropathy ready for optic nerve decompression were enrolled as controls [17]. In contrast, nasal administration of glucocorticoids increased the level of mucin recovered by nasal lavage of non-atopic subjects. In this study, subjects were randomized to receive either $200 \mu \mathrm{g}$ of fluticasone propionate once daily or $100 \mu \mathrm{g}$ of beclomethasone dipropionate twice daily to one nostril and placebo to the other, chosen randomly [18].

These human data in nasal cells are also in keeping with other studies performed in the lower airways of asthmatic patients. For example Groneberg et al. reported no change in MUC5AC protein expression in the bronchial biopsies after treatment with inhaled budesonide of asthmatic patients [19]. Also Fahy et al. did not observe any significant effect on mucin-like glycoproteins in the sputum of moderate asthmatics by inhaled beclomethasone dipropionate [20]. The functional role of MUC5AC in the nasal inflammation is still unknown but animal data suggests that this secretory mucin is not involved in the immune defenses of the upper airways [21] despite its potential protective role during influenza infection of the lower airways [22].
We did not observe any significant difference in the nuclear (an index of activation) or cytosolic distribution and expression of $\mathrm{p} 65$, one of the main subunits of NF$\mathrm{kB}$, both in the nasal epithelial and inflammatory cells in all the three groups of subjects. The absence of nuclear translocation of p65 in all subjects suggests that there was no spontaneous NF-kB activation during the collection and processing of the samples. This suggests that pro-inflammatory gene transcription and MUC5AC transcription in these groups of subjects are regulated by other pro-inflammatory transcription factors or pathways. The definitive way to determine the role of NF-kB or of any other transcription factor in driving MUC5AC expression is to perform chromatin immunoprecipitation (ChIP) analysis in these samples. Samples were not available for this study and there are concerns that the sensitivity of the assay would not allow detection in the small number of cells available from each subject.

Our study has several limitations. Firstly, this was an open study and the effects of nasal FF must be confirmed in a controlled clinical trial using a placebo arm and a cross-over design. In addition this was a pilot study examining a small number of patients. We also acknowledge the limitation that the mean age of the group of patients with persistent NAR under regular treatment with nasal FF is significantly, albeit slightly, higher compared with the control group of the healthy subjects and this may have influenced the results.

In addition we did not have any objective confirmation of patient compliance to nasal FF treatment. However the presence of reduced nasal symptoms, better quality of life scores and a decreased number of inflammatory cells observed in nasal scrapings, in the group of patients treated with nasal FF compared to untreated patients, suggest that these patients were, at least partially, compliant with this treatment. In summary our findings suggest the great potential for the use of nasal scrapings in investigating the molecular pathogenesis of persistent non-allergic rhinitis.

\section{Conclusions}

Patients with persistent untreated NAR, compared with normal control subjects and patients with persistent NAR under regular treatment with nasal fluticasone furoate by at least 20 days, have more nasal symptoms, worst quality of life and an increased number of nasal inflammatory cells (neutrophils, eosinophils), goblet cells and MUC5AC+ nasal epithelial cells. This nasal inflammation seems unrelated to NF-kB activation.

\section{Abbreviations}

$D A B, 3-3$ '-Diaminobenzidine; $F$, female; FF, fluticasone furoate; IgE, immunoglobulin $\mathrm{E} ; \mathrm{M}$, male; MUC5AC, mucin 5 AC; NAR, nonallergic rhinitis; NF-kB, nuclear factor-kappa B; PBS, phosphate-buffered saline; PFA, paraformaldehyde; RAST, RadioAllergoSorbent test; RQLQ, Rhinoconjunctivitis Quality of Life Questionnaire; SEM, standard error of the mean 


\section{Acknowledgements}

Research by KFC, PJB and IMA is supported by the NIHR Respiratory Disease Biomedical Research Unit at the Royal Brompton NHS Foundation Trust and the Imperial College London.

\section{Funding}

Fondo di Ateneo per la Ricerca scientifica (FAR) of the University of Ferrara, Italy (www.unife.it) granted to GC.

\section{Availability of data and material}

The data are all presented in the main paper and supplementary material.

\section{Authors' contributions}

Conceived and designed the protocol: GC DP. Recruited the Patients and the controls: DP, VI. Clinical procedures: DP, VI. Laboratory work: GC CP VI. Analyzed the data: GC IMA. Wrote the paper: GC IMA DP VI. Review of Manuscript: MC AP PJB KFC HHT SP AnP. All authors read and approved the final manuscript.

\section{Competing interests}

The authors declare that they have no financial or non-financial competing interests for this manuscript.

\section{Consent for publication}

Not applicable

\section{Ethics approval and consent to participate}

The study was approved by the local ethics committee of the University Hospital of Ferrara, Italy (www.ospfe.it), and informed consent was obtained from each participant in accordance with the principles outlined in the Declaration of Helsinki.

\section{Author details}

${ }^{1}$ ORL, Azienda USL Ferrara, Italy, Sezione di Scienze Otorinolaringoiatriche e Fisica Medica, Departimento di Scienze Biomediche e Chirurgico Specialistiche, University of Ferrara, Ferrara, Italy. ${ }^{2}$ Department of Biomedical Sciences, Faculty of Science and Engineering, University of Wolverhampton, Wolverhampton, UK. ${ }^{3}$ Airway Disease Section, National Heart and Lung Institute, Imperial College London, London, UK. ${ }^{4}$ Centre for Respiratory Infection, National Heart and Lung Institute at Imperial College, St. Mary's Hospital, Mint Wing, Entrance C, Paddington, London W2 1NY, UK. ${ }^{5}$ Centro Interdipartimentale per lo Studio delle Malattie Infiammatorie delle Vie Aeree e Patologie Fumo-correlate (CEMICEF), Dipartimento di Scienze Mediche, Sezione di Medicina Interna e Cardiorespiratoria, Università di Ferrara, Via Ludovico Ariosto 35, 44121 Ferrara, Italy. ${ }^{6}$ Sezione di Scienze

Otorinolaringoiatriche e Fisica Medica, Dipartimento di Scienze Biomediche e Chirurgico Specialistiche, University of Ferrara, Ferrara, Italy.

Received: 24 May 2016 Accepted: 29 July 2016

Published online: 04 August 2016

\section{References}

1. Greiwe J, Bernstein JA. Nonallergic Rhinitis: Diagnosis. Immunol Allergy Clin North Am. 2016;36:289-303.

2. Baroody FM. Nonallergic Rhinitis: Mechanism of Action. Immunol Allergy Clin North Am. 2016;36:279-87.

3. Gelardi M, Fiorella ML, Russo C, Fiorella R, Ciprandi G. Role of nasal cytology. Int J Immunopathol Pharmacol. 2010;23 Suppl 1:45-9.

4. Juniper EF, Thompson AK, Ferrie PJ, Roberts JN. Development and validation of the mini Rhinoconjunctivitis Quality of Life Questionnaire. Clin Exp Allergy. 2000;30:132-40.

5. Meltzer EO, Jalowayski AA. Nasal cytology in clinical practice. Am J Rhinol. 1988:2:47-54.

6. Caramori G, Romagnoli M, Casolari P, Bellettato C, Casoni G, Boschetto P et al. Nuclear localisation of p65 in sputum macrophages but not in sputum neutrophils during COPD exacerbations. Thorax. 2003:58:348-51.

7. Caramori G, Di Gregorio C, Carlstedt I, Casolari P, Guzzinati I, Adcock IM, et al. Mucin expression in peripheral airways of patients with chronic obstructive pulmonary disease. Histopathology. 2004;45:477-84.
8. Caramori G, Casolari P, Di Gregorio C, Saetta M, Baraldo S, Boschetto P, et al. MUC5AC expression is increased in bronchial submucosal glands of stable COPD patients. Histopathology. 2009;55:321-31.

9. Lohmann-Matthes ML, Steinmüller C, Franke-Ullmann G. Pulmonary macrophages. Eur Respir J. 1994;7:1678-89.

10. Mygind N, Nielsen LP, Hoffmann HJ, Shukla A, Blumberga G, Dahl R, et al. Mode of action of intranasal corticosteroids. J Allergy Clin Immunol. 2001;108 Suppl 1:S16-25.

11. Montalbano AM, Albano GD, Anzalone G, Bonanno A, Riccobono L, Di Sano $C$, et al. Cigarette smoke alters non-neuronal cholinergic system components inducing MUC5AC production in the $\mathrm{H} 292$ cell line. Eur J Pharmacol. 2014;736:35-43.

12. Ishinaga $\mathrm{H}$, Takeuchi $\mathrm{K}$, Kishioka C, Yagawa M, Majima Y. Effects of dexamethasone on mucin gene expression in cultured human nasal epithelial cells. Laryngoscope. 2002;112:1436-40.

13. Gollub EG, Waksman H, Goswami S, Marom Z. Mucin genes are regulated by estrogen and dexamethasone. Biochem Biophys Res Commun. 1995;217:1006-14

14. Kanoh S, Tanabe T, Rubin BK. IL-13-induced MUC5AC production and goblet cell differentiation is steroid resistant in human airway cells. Clin Exp Allergy. 2011:41:1747-56

15. Lu W, Lillehoj EP, Kim KC. Effects of dexamethasone on Muc5ac mucin production by primary airway goblet cells. Am J Physiol Lung Cell Mol Physiol. 2005;288:L52-60.

16. Singanayagam A, Glanville N, Bartlett N, Johnston S. Effect of fluticasone propionate on virus-induced airways inflammation and anti-viral immune responses in mice. Lancet. 2015;385 Suppl 1:S88.

17. Tang H, Wang H, Bai J, Ding M, Liu W, Xia W, et al. Nasal Health Group and China. Sensitivity of MUC5AC to topical corticosteroid is negatively associated with interleukin-17A in patients with allergic rhinitis. Am J Rhinol Allergy. 2012;26:359-64.

18. MacGregor FB, Robson AG, Pride NB. Topical corticosteroids potentiate mucin secretion in the normal nose. Clin Otolaryngol Allied Sci. 1996;21:76-9.

19. Groneberg DA, Eynott PR, Lim S, Oates T, Wu R, Carlstedt I, et al. Expression of respiratory mucins in fatal status asthmaticus and mild asthma. Histopathology. 2002;40:367-73.

20. Fahy JV, Boushey HA. Effect of low-dose beclomethasone dipropionate on asthma control and airway inflammation. Eur Respir J. 1998;11:1240-7.

21. Roy MG, Livraghi-Butrico A, Fletcher AA, McElwee MM, Evans SE, Boerner RM, et al. Muc5b is required for airway defence. Nature. 2014;505:412-6.

22. Ehre C, Worthington EN, Liesman RM, Grubb BR, Barbier D, O'Neal WK, et al. Overexpressing mouse model demonstrates the protective role of Muc5ac in the lungs. Proc Natl Acad Sci U S A. 2012;109:16528-33.

\section{Submit your next manuscript to BioMed Central and we will help you at every step:}

- We accept pre-submission inquiries

- Our selector tool helps you to find the most relevant journal

- We provide round the clock customer support

- Convenient online submission

- Thorough peer review

- Inclusion in PubMed and all major indexing services

- Maximum visibility for your research

Submit your manuscript at www.biomedcentral.com/submit
Biomed Central 